\title{
Usabilidade de espaleiras de violino e viola
}

\author{
Usability of violin and viola shoulder rest
}

Fausto Kothe 1

Clarissa Stefani Teixeira ${ }^{2}$

Érico Pereira Gomes Felden ${ }^{3}$

Eugenio Andrés Díaz Merino 4

1 Universidade Federal do Paraná, Curitiba, Paraná, Brasil
fausto.viola@gmail.com
${ }^{2}$ Universidade Federal de Santa Catarina, Florianópolis, Santa Catarina, Brasil
clastefani@gmail.com
${ }^{3}$ Universidade do Estado de Santa Catarina, Florianópolis, Santa Catarina, Brasil
ericofelden@gmail.com
${ }^{4}$ Universidade Federal de Santa Catarina, Florianópolis, Santa Catarina, Brasil
eugenio.merino@ufsc.br

\section{Resumo}

Os atributos necessários para o desenvolvimento de produtos podem ser avaliados e verificados por meio da usabilidade. No caso dos músicos de violino e viola, acessórios como a espaleira são necessários para melhorar o posicionamento, minimizar a tensão muscular na região do pescoço e liberar a mão esquerda para a digitação das notas. Mesmo assim, problemas como queixas musculoesqueléticas são indicados na literatura. Este estudo avaliou as espaleiras utilizadas por 10 músicos de uma orquestra, por meio dos princípios de usabilidade, e investigar a percepção dos músicos relacionada à satisfação, eficácia e eficiência das espaleiras, por meio de questionários com perguntas abertas. As problemáticas estão relacionadas à usabilidade, sendo as espaleiras consideradas eficazes para as práticas instrumentais, precisando ser mais eficientes, fazendo com que a correta postura seja 
mantida e que menores ocorrências musculoesqueléticas sejam geradas em função dos ajustes inadequados dos acessórios.

Palavras-chave: usabilidade em música; ergonomia em música; espaleira de violino e viola; acessórios de instrumentos musicais.

\section{Abstract:}

The attributes required for product development can be assessed and verified by usability. For musicians of violin and viola, accessories as shoulder rest are needed to improve the position, to minimize muscle tension in the neck and release the left hand for typing the notes. Even so problems such as musculoskeletal complaints are reported in the literature. Therefore, this study evaluated the shoulder rest used by 10 musicians from an orchestra using the principles of usability, and investigates the musicians perception related to satisfaction, effectiveness and efficiency of them, using questionnaires with open questions. The problems are related to usability being the shoulder rests considered effective to instrumental practice and they need to be more efficient, making the correct posture maintained and minor musculoskeletal events are generated due to the inadequate settings of accessories.

Keywords: usability in music; ergonomics in music; violin and viola shoulder rest;; accessories of music instruments.

Data de recebimento: 03/12/2014

Data de aprovação final: 23/09/2015

\section{1 - Introdução}

A usabilidade relaciona-se com os conceitos de eficácia, eficiência e satisfação atendendo as necessidades do usuário (ISO 9241-11:1998). Autores como PASCHOARELLI e COURY (2000) indicam que a usabilidade é a maximização da funcionalidade de um produto, na interface com seu usuário. Além disso, ANNA (2000) e KIM e HAN (2008) contextualizam que a usabilidade é um fator importante para o sucesso do produto. Para 
CYBIS, BETIOL e FAUST (2007) além desses conceitos, a usabilidade proporciona saúde e bem-estar, por meio da adaptação do trabalho.

Para o trabalho dos músicos de corda, especificamente do violino e viola, há necessidade de adequar os instrumentos ao homem (CAMPOS et al., 2006), visando à correta postura (BLUM e RITTER, 1990), e nesse sentido os conceitos de usabilidade são aplicados para o uso dos instrumentos de trabalho que, na área da música são os instrumentos musicais.

Os ajustes realizados nos instrumentos musicais são feitos por meio de acessórios acoplados tanto no violino quanto na viola e estes, mesmo que de forma lenta, vêm sendo modificados a longo dos anos. O estudo de REINA et al. (1988) mostrou que a utilização do instrumento diretamente sobre o corpo fazia com que houvesse obstrução da veia subclávica ou existência da chamada Síndrome de Paget-Schroetter. A amenização dos problemas relacionados à compressão indevida dos vasos se deu por meio da utilização de uma almofada/esponja entre o instrumento e o corpo. Com o tempo, a almofada foi substituída por equipamentos específicos. Durante o século XIX foi criada, por exemplo, a espaleira (objeto que o instrumentista apóia sobre os ombros) com o objetivo de facilitar a técnica da mão esquerda e permitir maior virtuosidade. A queixeira e a espaleira foram desenvolvidas na tentativa de tornar a postura mais natural, amenizando as estruturas musculoesqueléticas e permitindo liberação dos membros superiores para a realização efetiva das atividades (TEIXEIRA, 2011).

A queixeira, assim como ilustrada na Figura 1 (1a), é posicionada na parte frontal do instrumento e deve entrar em contato com o queixo. A espaleira (Figura 1 - 1b) por sua vez é posicionada na parte posterior do instrumento, e objetiva ocupar o espaço extra entre o instrumento e o ombro, firmar o instrumento, minimizando a tensão muscular, para que a mão esquerda seja liberada para deslocar no braço do instrumento e digitar as cordas. 


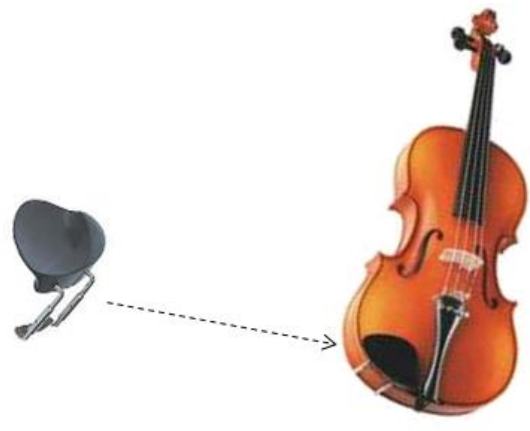

1a: Queixeira
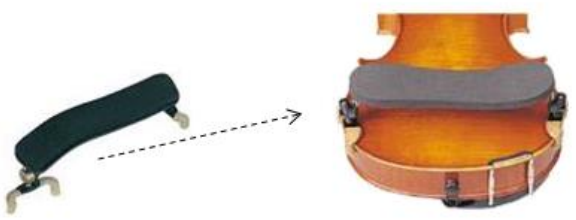

1b: Espaleira

Figura 1: Acessórios para a prática instrumental (TEIXEIRA, 2011).

Enquanto a maioria das queixeiras se limita a regulagens, as espaleiras são projetadas para a acomodação do instrumento sobre o ombro apresentando um número maior de possibilidades para adaptação ao corpo. Segundo OKNER, KERNOZEK e WADE (1997) o tamanho da espaleira deve prover fricção entre o instrumento e o ombro do artista, de forma que excessivo deslizando é prevenido.

Porém, mesmo que as possibilidades de regulagens existam, há necessidade de maiores esclarecimentos da utilização da espaleira, relacionadas à sua usabilidade, eficiência, eficácia e satisfação, uma vez que problemas estão sendo identificados em função da utilização da mesma, principalmente relacionados aos ajustes necessários para adequação da postura de forma correta (STEINMETZ, SEIDEL e NIEMIER, 2008).

Diante dessas premissas, a ergonomia tenta buscar e assegurar que a utilidade dos produtos e a qualidade da interação estejam adequadas aos requisitos do usuário, às exigências da tarefa e ao contexto em que o produto será usado. Para tanto, surge a necessidade de investigações relacionadas aos acessórios que os músicos fazem uso para o fazer musical. Logo, este estudo objetivou avaliar as espaleiras utilizadas pelos violinistas e violistas, por meio dos princípios de usabilidade, bem como, investigar a percepção dos instrumentistas relacionada à satisfação, eficácia e eficiência das espaleiras utilizadas. 


\section{2 - Metodologia}

Este estudo caracteriza-se, segundo THOMAS e NELSON (2002), como um estudo descritivo-exploratório, de corte transversal, no qual foi realizado um levantamento de informações ainda pouco investigadas em uma determinada população.

O estudo foi realizado com músicos de uma orquestra da região sul do Brasil. Esta orquestra é composta por 29 instrumentistas dos seguintes instrumentos: cordas, sopros, metais e percursão. As cordas são constituídas por cinco naipes diferentes, sendo eles primeiros violinos, segundos violinos, violas, violoncelo e contrabaixo. Como a espaleira não é utilizada pelos instrumentistas de violoncelo e contrabaixo, neste estudo, foram avaliados os naipes dos violinos e viola, que totalizam 13 instrumentistas (nove violinos e quatro violas). Destes, 10 instrumentistas aceitaram em participar do estudo, sendo quatro músicos de viola e seis de violino.

Para o direcionamento do estudo, foram realizadas quatro etapas distintas de análise, sendo a etapa 1 associada a análise do perfil do usuário e contexto da tarefa, a etapa 2 associada a avaliação dos princípios da usabilidade por meio de especialistas, a etapa 3 associada a percepção dos instrumentistas no que tange a eficiência, eficácia e satisfação das espaleiras e, a etapa 4, associada a identificação das queixas musculoesqueléticas e suas relações com os acessórios.

Primeiramente, na etapa 1, foi realizada uma análise do perfil do usuário para se conhecer os atributos pessoais e suas habilidades e competências, segundo indicação de CYBIS, BETIOL e FAUST (2007). Conforme indicação dos mesmos autores foi realizada uma breve análise do contexto da tarefa, para se conhecer principalmente os objetivos, resultados, duração e estrutura das atividades, assim como uma análise das possibilidades e restrições das espaleiras utilizadas pelos músicos.

Considerando a etapa 2, foram identificadas as marcas de espaleiras utilizadas pelos instrumentistas. Em todas as marcas foram aplicados os 10 princípios usabilidade propostos 
por JORDAN (1998). A avaliação da usabilidade foi realizada por três especialistas da área de ergonomia. Estas avaliações seguiram as definições estabelecidas na Figura 2.

\begin{tabular}{|c|c|}
\hline \multicolumn{2}{|c|}{$\begin{array}{l}\text { Princípios de usabilidade considerados pelos especialistas para a análise das } \\
\text { espaleiras }\end{array}$} \\
\hline Consistência & $\begin{array}{l}\text { Projetar um produto para a consistência significa que tarefas } \\
\text { similares devem ser executadas de modos similares. }\end{array}$ \\
\hline Compatibilidade & $\begin{array}{l}\text { A maneira como o produto compatível funciona deve corresponder } \\
\text { à expectativa do usuário, criada a partir das experiências vividas. }\end{array}$ \\
\hline Capacidade & $\begin{array}{l}\text { O usuário possui determinadas capacidades para cada função, que } \\
\text { devem ser respeitadas. É importante que ao usar um produto, o } \\
\text { consumidor não tenha suas capacidades suprimidas ou } \\
\text { ultrapassadas. }\end{array}$ \\
\hline $\begin{array}{l}\text { Retro- } \\
\text { alimentação }\end{array}$ & $\begin{array}{l}\text { É importante que as interfaces retornem aos usuários informações } \\
\text { sobre o resultado de qualquer ação por eles tomada. }\end{array}$ \\
\hline $\begin{array}{l}\text { Prevenção e } \\
\text { correção de } \\
\text { erros }\end{array}$ & $\begin{array}{l}\text { Os produtos devem ser projetados de forma que a possibilidade de } \\
\text { ocorrência de erros seja minimizada e que o usuário possa corrigir } \\
\text { os eventuais erros de forma rápida e fácil. }\end{array}$ \\
\hline $\begin{array}{l}\text { Controle ao } \\
\text { usuário }\end{array}$ & $\begin{array}{l}\text { Os usuários devem ter o máximo controle possível sobre as } \\
\text { interações que terá com o produto. }\end{array}$ \\
\hline Clareza visual & $\begin{array}{l}\text { A informação deve ser disponibilizada de maneira que possa ser lida } \\
\text { de forma rápida e fácil, sem causar confusão quanto ao seu } \\
\text { entendimento. }\end{array}$ \\
\hline $\begin{array}{l}\text { Priorização da } \\
\text { funcionalidade e } \\
\text { da informação }\end{array}$ & $\begin{array}{l}\text { Produtos com grande variedade de funções devem estar apropriados } \\
\text { para priorizar alguma destas funções ao se projetar a interface do } \\
\text { produto. }\end{array}$ \\
\hline $\begin{array}{l}\text { Transferência } \\
\text { adequada de } \\
\text { tecnologia }\end{array}$ & $\begin{array}{l}\text { A assimilação de tecnologias desenvolvidas para outras áreas pode } \\
\text { potencialmente trazer grandes benefícios aos usuários e suas } \\
\text { possíveis conseqüências e problemas. }\end{array}$ \\
\hline Evidência & $\begin{array}{l}\text { A solução formal do produto deve indicar claramente a sua função } \\
\text { e o modo de operação. }\end{array}$ \\
\hline
\end{tabular}

Figura 2: Quadro com as definições dos princípios de usabilidade que foram considerados pelos especialistas (JORDAN, 1998). 
Considerando a etapa 3, foi realizada a aplicação de um questionário com perguntas abertas que identificava a percepção de satisfação, eficácia e eficiência da espaleira. Além disso, foram aplicadas questões relacionadas ao comportamento dos instrumentistas na decisão da compra e a utilização da espaleira durante as práticas instrumentais.

Já a etapa 4, que buscou identificar a ocorrências de sintomas musculoesqueléticos, foi realizada em função das indicações da literatura que contextualiza que as dores e/ou desconfortos podem se relacionar diretamente com os ajustes posturais frente aos equipamentos de trabalho (TEIXEIRA, 2011). Para esta etapa, foi aplicado o questionário desenvolvido por CORLETT e BISHOP (1976) que identifica a dor/desconforto corporal. Para este estudo foi levado em consideração apenas o fato de sentir ou não sentir dor e/ou desconforto nas regiões corporais relacionadas com a manutenção do instrumento (pescoço, ombro esquerdo, braço esquerdo e região superior das costas).

\section{3 - Resultados}

\section{1 - Análise do perfil dos instrumentistas}

Para a realização do trabalho de orquestra, há necessidade de qualificação profissional (formação superior, escolas específicas de música - os chamados conservatórios ou estudos com professores qualificados), que muitas vezes, demanda anos de prática, experiência e dedicação. Não há prevalências de gêneros, faixa etária ou limitações antropométricas para o ingresso nas atividades. Apenas se deve apresentar tempo disponível para que, durante os ensaios, haja interpretação da partitura musical de forma satisfatória, assim como durante as apresentações, sendo que a avaliação do desempenho dos músicos é normalmente avaliada pelo maestro que rege a orquestra (TEIXEIRA, 2011).

Os músicos avaliados formam um grupo de 10 indivíduos, com predominância do instrumento violino, já observado em outros estudos (HUNTER e FRY, 1986; BLUM e RITTER, 1990; HEMING, 2004). Estas características se devem pela exigência da maioria 
das obras que centra a carga de trabalho principalmente nos violinos. Os violinistas (quatro músicos e duas musicistas) e violistas (quatro músicos) apresentam idades entre 15 e 45 anos (média de 24,27 \pm 10,09 anos), tocam o instrumento a 6,09 \pm 6,95 anos (máximo de 25 anos e mínimo de um ano) e tocam na orquestra a 2,91 $\pm 2,39$ anos.

\section{2 - Análise do contexto da tarefa}

A tarefa dos músicos, indicada por GUÉRIN et al. (2001) e IIDA (2005), é a execução da obra musical. Para tanto, o trabalho dos músicos deve ser desenvolvido de tal forma que haja esforços individuais e coletivos, visto que todos os instrumentistas atuam buscando o mesmo objetivo, ou seja, construir a interpretação da obra (COSTA, 2003; PETRUS, 2005). Para que isto ocorra, a integração de todos os naipes de instrumentos, os quais se articulam frente às determinações da obra musical e da interpretação dada pelo maestro, é fundamental. Mesmo com a especialização instrumental, todos os esforços individuais convergem para a construção sonora da obra musical, o que caracteriza uma atividade coletiva de trabalho de integração e harmonia entre as partes.

As atividades dos músicos avaliados são desenvolvidas em quatro momentos distintos: 1) práticas individuais; 2) práticas com o naipe; 3) práticas coletivas com toda a orquestra e; 4) apresentações. Os músicos realizam suas atividades individuais durante 2,27 $\pm 2,15$ horas por dia, 5,27 $\pm 1,27$ dias na semana. Os estudos coletivos (de naipe e ensaios com a orquestra) totalizam 3,64 \pm 0,92 horas. Para todas essas práticas, além do instrumento e arco utilizado para a concretização do som, os acessórios (espaleira e queixeira) são utilizados.

Nos 10 instrumentistas avaliados, foram identificadas duas marcas diferentes de espaleiras, porém com os mesmos sistemas de regulagens (sistema de rosca), sendo diferenciadas apenas pelo formato, assim como ilustra a Figura 3, sendo a espaleira B com formato mais antropomorfo que a espaleira A, ou seja, a espaleira B apresenta pequenas curvaturas que objetiva maior adequação a estrutura corporal. 


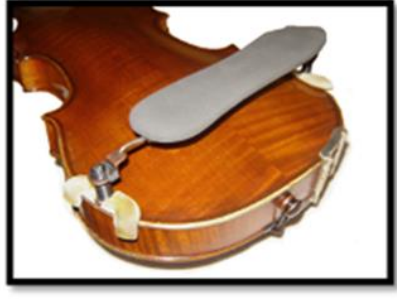

Espaleira A - sem curvatura

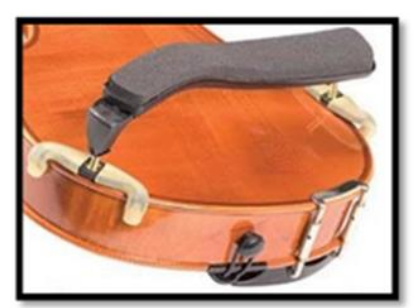

Espaleira B - com curvatura

Figura 3: Espaleiras utilizadas pelos instrumentistas avaliados.

Os materiais de acabamento da espaleira são diferentes considerando aqueles que ficam em contato com o instrumento e aqueles que ficam em contato com o instrumentista. Ambas as espaleiras são constituídas de resina de etileno acetato de vinila (EVA) na base de suporte que entra em contato com o ombro do músico e, em contato com o instrumento os materiais são leves, constituídos de metal, com proteção de borracha, para não arranhar o instrumento.

\section{3 - Análise das possibilidades e restrições}

Nas espaleiras, de forma geral, há possibilidades de duas regulagens indicadas por CAMPOS et al. (2006). Dentre elas, podem ser citadas as regulagens na altura, utilizadas para adaptar a posição do instrumento em relação à dimensão antropométrica do pescoço. Estas regulagens são realizadas por meio de eixos roscados posicionados nas extremidades da espaleira, assim como ilustra a Figura 4.

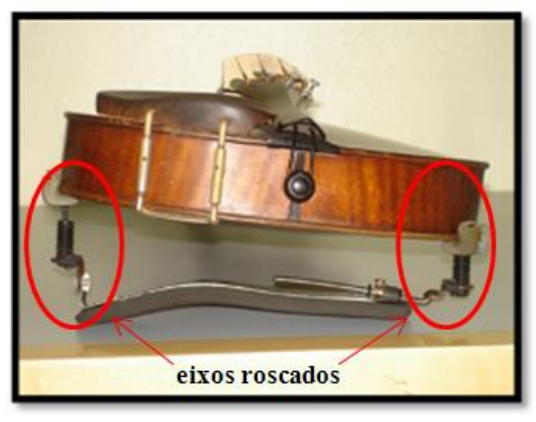

Figura 4: Eixos roscados para ajustes da altura da espaleira. 
As regulagens laterais (em função da largura, forma e curvatura de cada instrumento) também são encontradas nas espaleiras avaliadas (Figura 5). É importante salientar que as dimensões dos próprios instrumentos são diferenciadas entre violino e viola e também existem diferenças entre os próprios instrumentos, conforme relatado no estudo de TEIXEIRA (2011). As dimensões de viola para viola, por exemplo, podem variar de 39 a 44 cm (BLUM e RITTER, 1990), por isso a necessidade de ajustes laterais.

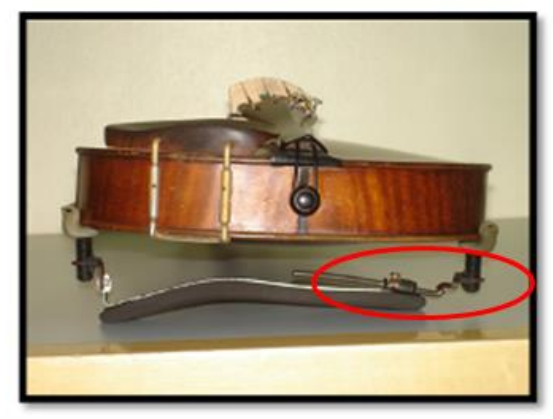

Figura 5: Regulagem da espaleira para ajuste lateral.

Além disso, conforme necessidade dos instrumentistas há possibilidade de modificar essas posições, assim como ilustra a Figura 6. As regulagens de profundidade, relacionadas ao contato com o ombro dos instrumentitsas, não são possíveis em nenhuma das espaleiras avaliadas, pois estas são feitas com materiais sem possibilidade de maleabilidade. Neste sentido, apenas há diferenciação das marcas relacionadas às curvaturas de uma e de outra, assim como ilustrou a Figura 3.

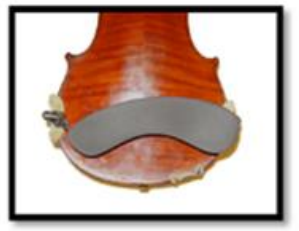

A - horizontal

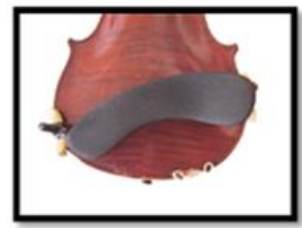

B - diagonal

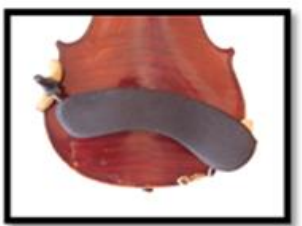

C - diagonal

Figura 6: Posicionamentos da espaleira horizontal em relação ao instrumento e posicionamento da espaleira diagonal em relação ao instrumento. 


\section{4 - A usabilidade aplicada as espaleiras}

De acordo com os princípios de JORDAN (1998), avaliados pelos especialistas, pode-se analisar que:

1) Princípio de Consistência: No caso das espaleiras avaliadas a consistência entre os acessórios parece ser atendida de forma que os ajustes são realizados de forma similar, podendo-se modificar as regulagens para adequação na altura e na lateral;

2) Princípio de Compatibilidade: De maneira geral, para o atendimento desse princípio é importante observar que $40 \%$ dos músicos apresentam seu primeiro contato com a espaleira atual. Para as atividades, $40 \%$ dos músicos fizeram uso de três modelos diferentes de espaleiras; $10 \%$ de seis modelos e; $10 \%$ de dois modelos diferentes para as práticas instrumentais até chegar no modelo atual. Portanto, para corresponder às expectativas dos músicos, de forma geral, há necessidade de se ter uma espaleira que favoreça o posicionamento correto do instrumento, sem desconforto corporal. A expectativa de se obter um produto melhor será válida apenas para aqueles músicos que já tiveram contato com outras espaleiras, sendo esses $60 \%$ dos músicos avaliados;

3) Princípio de Capacidade: Neste caso, é importante salientar a capacidade que cada instrumentista tem para determinar o correto ajuste do instrumento. As dores e/ou o desconforto musculoesquelético, na região do pescoço, ombro e região superior das costas, relatado pelos músicos, podem estar relacionadas, dentre outros fatores, ao ajuste incorreto da espaleira, que propicia posicionamentos corporais inadequados, exigindo mais das estruturas musculoesqueléticas e articulares. As dores relatadas no braço também podem estar relacionadas a estes ajustes, fazendo com que o membro superior esquerdo, além de digitar as notas, dê suporte para que o instrumento permaneça na posição indicada, ou seja, horizontalizada e paralela ao solo. Portanto a capacidade de escolha do melhor ajuste pode ficar prejudicada e, nesse caso, estudos específicos que venham a definir e quantificar as corretas posturas corporais ainda precisam ser desenvolvidos. Outro ponto importante de consideração se associa a necessidade de se considerar os instrumentistas de forma 
individualizada visto que as estruturas corporais, histórico de aprendizgem e experiência, instrumentos e acessórios são diferentes;

4) Princípio de Retro-alimentação: Nas espaleiras, o feedback é uma problemática, pois além de não existir nenhuma indicação de possíveis erros entre posicionamento e postura adotada para a prática instrumental, também não há na literatura consultada indicações de como se proceder para a obtenção dos corretos ajustes para as diferentes estruturas corporais (antropometria) e nas diferentes dimensões de instrumentos musicais. As únicas indicações de que a postura não está adequada são relacionadas às excessivas angulações da coluna cervical, ou até mesmo com os sintomas de dor/desconforto, que muitas vezes indicam problemas de posicionamento. Nesses casos, vale salientar que a percepção do próprio músico para com sua postura e posicionamento do instrumento é usada como determinante dos ajustes com os acessórios (queixeira e espaleira);

5) Princípio de Prevenção e correção de erros: Este princípio não é atendido e vem ao encontro dos problemas identificados na retro-alimentação (feedback). O caso da correção e prevenção de erros é, muitas vezes, identificado apenas com o sentimento e queixas desconforto, dores ou até mesmo com os adoecimentos, comuns na profissão. Este princípio solicita consciência corporal do músico, o que segundo STEINMETZ, SEIDEL e NIEMIER (2008), não é encontrada nestes profissionais. Mais uma vez, este é um empecilho encontrado para o ajuste do acessório o que necessita de avaliações externas, como de professores para o correto ajuste;

6) Princípio de Controle ao usuário: Mesmo que os músicos saibam das possibilidades de ajustes da espaleira, muitas vezes o que ocorre é o desconhecimento de como essa necessita interagir com o corpo e com o instrumento de forma a priorizar além do suporte ao instrumento a postura corporal. Logo, há percepção de se regular conforme o sentimento de desconforto, como vislumbrado por $50 \%$ dos músicos, que ajustam a espaleira para que não haja desconforto corporal. Porém, como nem sempre o que é confortável é seguro (VAN DER LINDEN e GUIMARÃES, 2006), o controle realizado pelos instrumentistas, que buscam o conforto durante as práticas, deve ser estudado de forma mais aprofundada; 
7) Princípio de Clareza visual: A aplicação deste princípio é limitada. Na verdade a clareza visual deve estar nos ajustes necessários, que no caso das espaleiras não há nenhum tipo de simbologia que indique onde e como esses devem ser realizados;

8) Princípio de Priorização da funcionalidade e da informação: Este princípio é atendido de forma que a funcionalidade da espaleira é dar suporte ao instrumento, procurando maximizar a correta postura para a prática do instrumento, com mínimas modificações da angulação da cervical, liberando a mão esquerda para a digitação. Uma característica que deve ser levada em consideração é que este é o princípio que faz com que os instrumentistas utilizem esse acessório durante as praticas;

9) Princípio de Transferência adequada de tecnologia: A tecnologia atual poderia ser utilizada de forma a preconizar os melhores ajustes do acessório com as diferentes estruturas corporais. Porém, como observado na Figura 3, os materiais utilizados para a fabricação da espaleira, podem ser considerados simples e podem ainda ser melhorados. Além disso, nesse mesmo sentido, ainda são necessários o desenvolvimento de acessórios que considerem a maior gama da população (dados antropométricos versus dimensões dos instrumentos violino e viola);

10) Princípio de Evidência: No geral, pode-se dizer que ambas as espaleiras atendem às necessidades dos instrumentistas, porém estas precisam ainda ser melhoradas, principalmente na adequação das diferentes estruturas corporais e identificações dos melhores ajustes conforme as diferenças individuais.

\section{5 - Percepção da satisfação, eficácia, eficiência e comportamento para decisão de compra e utilização das espaleiras}

As maiores problemáticas das espaleiras avaliadas, segundo seus usuários - os instrumentistas - estão relacionadas em identificar quais os corretos ajustes que devem ser feitos para as diferenças antropométricas dos indivíduos, o que pode influenciar diretamente na sensação de conforto e consequentemente na satisfação para com o produto. 
De acordo com as respostas indicadas pelos músicos se pode perceber que para $90 \%$ dos músicos as espaleiras são eficazes para as práticas instrumentais, porém com as adaptações de usabilidade podem se tornar mais eficientes, fazendo com que não só a correta postura seja mantida, mas também que menores ocorrências de dores e/ou desconfortos musculoesqueléticos sejam geradas em função dos ajustes inadequados dos acessórios.

Na percepção de $70 \%$ dos músicos algumas modificações como maior regulagem na altura, materiais diferenciados, encostos mais flexíveis para o melhor ajuste do ombro, poderiam ser adotadas. Para os músicos, a espaleira ideal deveria ter: i) moldes individuais, ii) maiores curvaturas para a dimensão dos ombros, iii) maior conforto; iv) custo baixo; v) facilidade nos ajustes.

$70 \%$ dos músicos acreditam que os materiais que a espaleira é constituída são adequados, mas demonstram que os materiais poderiam ser trocados visando maior conforto e adaptação ao corpo. Observa-se que, de maneira geral, os instrumentistas acreditam que é melhor utilizar a espaleira atual do que não utilizar nenhum acessório, visto que as espaleiras e as queixeiras servem para minimizar as posturas incorretas e favorecer as interações com o instrumento.

O conforto, a adaptação e o fato de não sentir dores são os motivos que induzem os instrumentistas a afirmar que estão fazendo uso das regulagens corretas para as suas dimensões corporais. Além disso, 90\% dos músicos afirmam não possuírem dores relacionadas à região de contato com a espaleira (ombro e/ou clavícula), o que indica que possivelmente não há pressões elevadas durante o contato com o acessório.

Entretanto, as queixas musculoesqueléticas são percebidas pelos instrumentistas o que demonstra que mesmo com a utilização de acessórios há acometimentos físicos. Essas informações são preocupantes tendo em vista o elevado número de instrumentistas que percebem as regiões como sendo dolorosas com a prática dos instrumentos. A Figura 7 ilustra o percentual de instrumentistas que sentem dor e as regiões corporais percebidas como sendo dolorosas. 


\begin{tabular}{lc}
\hline Região corporais acometidas & Instrumentistas (percentual) \\
\hline Pescoço (cervical) & $80 \%$ \\
Ombro esquerdo & $70 \%$ \\
Braço esquerdo & $50 \%$ \\
Região superior das costas & $70 \%$ \\
\hline
\end{tabular}

Figura 7: Queixas musculoesqueléticas por região corporal dos instrumentistas.

Esses achados indicam preocupações relacionadas à satisfação do acessório, uma vez que, segundo JORDAN (1998) a satisfação é considerada como nível percebido de conforto. Entretanto, o que se observa é que na profissão da música, as associações entre produto e desconforto ainda não são percebidas de forma clara. Nesse sentido, autores como FRY (1986a) e FRY (1986b) já indicam que na música as queixas são encaradas como sendo normais da profissão. O estudo de ANDRADE e FONSECA (2000) demonstrou que muitos instrumentistas acreditam que as queixas podem ser dissipadas normalmente, ou seja, sem intervenções médicas ou fisioterapeuticas, o que pode acarretar em agravos dos quadros de saúde-doença. Além disso, o tempo de permanência em posturas isométricas, que desfavorecem a biomecânica corporal, pode ser aliado aos problemas musculoesqueléticos encontrados.

Os procedimentos de ajustes da espaleira, realizadas entre o instrumento e ombro, são observados principalmente com a modificação da altura da espaleira. $100 \%$ dos músicos afirmam que os ajustes são realizados principalmente na altura da espaleira, ou seja, nos dois eixos roscados, assim como ilustrou a Figura 4. A posição horizontalizada da espaleira foi testada por $70 \%$ dos músicos, assim como na Figura 6. Posicionamentos na diagonal (Figura b) foi testado por $20 \%$ dos músicos e na Figura c por $50 \%$ dos músicos.

Para o ajuste da espaleira, 40\% dos instrumentistas indicaram que o professor auxiliou na definição do posicionamento. $60 \%$ fizeram os ajustes sem auxílio de outras pessoas e buscaram, para a definição do posicionamento atual, o conforto ou ausência de desconforto. $90 \%$ julgam estar utilizando a regulagem correta e 10\% afirmaram não saber. Entretanto, 
vale salientar que mesmo que hajam essas percepções os sintomas musculoesqueléticos estão presentes. $80 \%$ dos músicos gostariam que houvesse um manual com indicações dos ajustes para as diferenças de antropometria corporal e de dimensões dos instrumentos.

Para a aquisição da espaleira o preço é um dos fatores decisivos e que consequentemente irão influenciar na compra para $30 \%$ dos músicos. A indicação de outras pessoas, como no caso do presente estudo - do professor, também influenciou a aquisição da espaleira atual. A indicação chamada de "boca-a-boca" por PADILHA (2001) demonstra a credibilidade do produto. No caso dos músicos, a indicação do professor determinou a compra de $40 \%$ das espaleiras atuais utilizadas.

A escolha da espaleira, para 50\% dos instrumentistas, também é determinada pelo conforto e a ergonomia, o que remete a busca pela satisfação ao adquirir um novo acessório. Além destas considerações, foram citados o peso da espaleira e os limites de inclinação que a espaleira pode proporcionar, o que segundo relatos leva a uma instabilidade do instrumento. A maior evidência foi relacionada à adequação da espaleira no ombro, de forma que não haja desconforto e para tanto, conforme verbalizações há necessidade de um contato total entre a espaleira e o ombro. Esta necessidade demonstrada pelos instrumentistas não é atendida em nenhuma das espaleiras avaliadas, mesmo sendo a espaleira $\mathrm{B}$, mais antropomorfa que a espaleira A, assim como ilustrou a Figura 3.

\section{4 - Discussão}

Para IIDA (2005) a usabilidade não depende unicamente das características do produto. Depende também do usuário, dos objetivos pretendidos e do ambiente em que o produto é usado. Portanto, implica otimizar as interações estabelecidas pelos indivíduos com produtos interativos, de modo a permitir que realizem suas atividades no trabalho, na escola e em casa (PREECE, ROGERS e SHARP, 2005). 
De maneira geral, há indicações da necessidade de todo e qualquer projeto estar focado no usuário, já que as pessoas que utilizam produtos o fazem para ser mais produtivas em suas tarefas e, em última análise, são elas próprias que decidem quando um produto é eficiente, eficaz e satisfatório (JORDAN, 1998; PADILHA, 2001). Em música, e em especial nos instrumentistas de violino e viola, essas informações não são diferentes para os acessórios utilizados durante as práticas performáticas. No caso da espaleira, estas questões estão relacionadas principalmente ao posicionamento da mesma no instrumento, que por sua vez, determina o posicionamento corporal adequado para a prática instrumental.

Além disso, pode-se dizer que a espaleira deve agir de forma eficaz, pois possibilita que o músico desenvolva a atividade - tocar seu instrumento. Porém, as queixas musculoesqueléticas, principalmente na região do pescoço, responsáveis pela contração muscular que auxilia a preensão do instrumento, demonstra que a eficiência desse acessório necessita ser melhorada com intuito de se minimizar os impactos da atividade e otimizar a postura para o tocar. Para BRANDFONBRENER (1989) os problemas encontrados no pescoço dos músicos estão relacionados à postura exigida para segurar o instrumento. Segundo TEIXEIRA, MERINO e LOPES (2008) os problemas de postura relacionados ao posicionamento da espaleira também devem ser melhor investigados, pois de acordo com VERGARA e PAGE (2002) grandes alterações de postura são bons indicadores de desconforto.

De acordo com as avaliações de usabilidade do presente artigo, há necessidade de algumas melhorias nos princípios propostos por JORDAN (1998) de forma que a espaleira torne-se, assim como indica IIDA (2005) o mais amigável possível e de fácil utilização/operação, entendimento e interação. De acordo com a análise dos princípios indicados na Figura 2, pode-se indicar melhoras na capacidade de escolha do melhor ajuste para a dimensão corporal do músico; na retro-alimentação que, muitas vezes ocorre com a percepção de dor/desconforto pelo posicionamento inadequado da espaleira e que se relaciona às problemáticas da prevenção e correção de erros; no controle do usuário, que regula a espaleira de modo a perceber menor desconforto durante a prática; e na clareza visual que facilite os ajustes a serem realizados. Não só há identificação das possíveis melhoras no 
produto, mas também há necessidade em modificações da estrutura da espaleira, visando maior conforto e adaptabilidade, principalmente entre o contato do ombro com o acessório.

Para SILVEIRA (2008) a usabilidade pode ser atingida focando nas interações entre o indivíduo, o artefato, o ambiente e a tarefa. No caso do trabalho dos instrumentistas, há necessidade de interações específicas do músico com os acessórios (espaleira e queixeira), o posto de trabalho (cadeira, estante, partitura, orquestra, maestro) e a tarefa a ser desenvolvida - a obra musical.

COSTA (2003) indica que o uso de artefatos auxiliares para encaixe do instrumento ao corpo, como a espaleira e a queixeira, são recursos utilizados pelos músicos para adaptação do instrumento às suas características físicas. Os ajustes possibilitados pelo tamanho, textura de material e regulagens visam propiciar maior conforto durante o tempo de execução. A regulação destas variáveis deve ser de cunho estritamente individual, o que segundo os músicos é fundamental para o acerto de posicionamento do instrumento.

Não só o design da espaleira pode ser atribuído como uma das causas de dores dos instrumentistas. OKNER, KERNOZEK e WADE (1997) consideram que a exigência da obra musical influencia a força e pressão exercida nos utensílios (queixeira e espaleira) dos instrumentos de cordas, ou seja, quanto mais difícil tecnicamente a composição musical maior é a pressão e a força exercida pelo músico, o que consequentemente pode gerar tensão excessiva na região das costas (trapézio, rombóides, elevador da escápula), pescoço (principalmente oblíquo inferior da cabeça, lado direito do esternocleidomastóideo e esplênio esquerdo) e região mandibular. Logo, acessórios confortáveis e que favoreçam a postura e o posicionamento do instrumento no corpo do músico é fundamental.

Para BERKHOUT, HENDRIKSSON-LARSÉN e BONGERS (2004) diferentes ajustes ou modelos de queixeira e/ou espaleira poderiam ser pensados, tanto para um maior conforto quando para menores riscos musculoesqueléticos. Mesmo que haja indicações de usos destes utensílios para facilitar o trabalho e diminuir as queixas, parece que as questões de usabilidade das queixeiras e espaleiras ainda devem ser repensadas, pois algumas das 
problemáticas que envolvem os adoecimentos podem ser relacionadas ao uso destes equipamentos (LEVY et al., 1992; BRANDFONBRENER, 1999).

A antropometria do pescoço, do queixo e do ombro dos instrumentistas pode ser uma medida relacionada e melhor investigada para a escolha e utilização da espaleira (COSTA, 2003). Isto é identificado no presente estudo, uma vez que, a ergonomia foi um dos fatores que segundo os músicos, contribuem para a escolha dos acessórios.

Andrade e FONSECA (2001) consideram que as causas de dor, tensão e fadiga nos instrumentistas de cordas são relacionadas à má postura durante a execução do instrumento, decorrentes de vícios técnicos de execução e inadequações entre as medidas dos acessórios do violino (queixeira e espaleira) com as medidas antropométricas dos instrumentistas. NORRIS (1995) indica que as queixas na cervical são em função da queixeira que não é usada de forma amigável. O mesmo autor observa que em alguns instrumentistas de violino e viola a queixeira é utilizada de forma muito alta o que prejudica a postura corporal. Desta forma, o autor menciona que os acessórios devem ser utilizados conforme o dimensionamento corporal de cada indivíduo. Segundo WINSPUR e PARRY (1997) indivíduos com estaturas acima de $1,78 \mathrm{~cm}$ e com pescoços considerados mais longos podem apresentar problemas de ordem musculoesquelética devendo fazer uso de queixeiras e espaleiras adaptadas para suas dimensões corporais.

Além disso, para COSTA (2003) alturas adequadas da espaleira podem aliviar o desconforto, mesmo que haja um aumento de $20 \%$ do peso do instrumento. Mesmo que a maioria dos músicos afirme que a espaleira esteja regulada de forma correta, estudos mais abrangentes podem ainda ser realizados, uma vez que, um elevado índice de queixas de dor e/ou desconforto foi relatado pelos músicos, tanto na região do pescoço, parte superior das costas quanto no ombro esquerdo. Estas problemáticas evidenciam atitudes que merecem atenção, uma vez que, podem comprometer e impedir a realização das atividades profissionais.

Além da inadequação dos acessórios, as causas das queixas musculoesqueléticas podem estar relacionadas tanto às posturas durante as práticas musicais, quanto ao excesso de tensão realizado para tocar o instrumento (ARAÚJO e CARDIA, 2005). Neste sentido, reflexões 
sobre o posicionamento corporal e a atuação muscular ainda necessitam ser feitas. Para FJELLMAN-WIKLUND et al. (2004) durante a prática instrumental foram encontradas diferenças entre os lados direito e esquerdo da ativação muscular do músculo trapézio, demonstrando que há assimetrias durante a execução do movimento dos membros superiores. Neste contexto, para que o instrumento fique ajustado ao instrumentista, a musculatura do lado esquerdo dos membros superiores age isometricamente durante toda a atividade de trabalho (FJELLMAN-WIKLUND et al., 2004).

Não só isto, a situação é mais intensa se os acessórios estiverem desajustados e, neste caso, há uma compensação da musculatura do ombro esquerdo, que acaba sendo sobrecarregada. Segundo TEIXEIRA et al. (2009) movimentos de elevação e rotação interna de ombro são muitas vezes observados em músicos de violino e viola, com o intuito de aproximar o instrumento do queixo. Além disso, segundo os mesmos autores, são evidenciadas flexões e rotações indevidas da coluna cervical, agravando mais ainda o quadro de queixas. Além disso, o estudo de TEIXEIRA et al. (2012) indicaram que o ângulo da cervical, por exemplo, durante as práticas instrumentais permanece com valores acima daqueles indicados pela literatura o que se associa diretamente com as queixa de dor percebidas pelos instrumentistas.

STEINMETZ, SEIDEL, e NIEMIER (2008) ao identificarem incompatibilidades entre queixeira e dimensões corporais do músico avaliado, por meio da angulação da cervical, aumentaram a altura da queixeira com intuito de aproximar a mesma do queixo. Diante destas atitudes, há necessidade de investigações mais aprofundadas, principalmente relacionadas com as diferenças individuais dos músicos. Ademais, os mesmos autores já percebem que essas ações são necessárias e podem otimizar o trabalho com a música.

Para PHILIPSON et al. (1990) e BERQUE e GRAY (2002) existe uma considerável variabilidade inter-individual na ativação muscular do trapézio. Segundo os autores as maiores variações estão relacionadas à dificuldade das obras, ou seja, em obras consideradas mais fáceis foi encontrada menor ativação muscular, enquanto em obras mais difíceis houve maior ativação do trapézio. Para OKNER, KERNOZEK e WADE (1997) o repertório musical é considerado um parâmetro crítico para os níveis de força e pressão na região da queixeira e espaleira durante a prática instrumental. Logo, obras que exigem maiores 
condições técnicas somadas às inadequações dos acessórios podem gerar problemas, como dor, desconforto e até mesmo adoecimentos. Entretanto, a dificuldade das obras não é prática controlável pelos instrumentistas. Apenas a técnica para com o instrumento pode ser treinada e consequentemente aprimorada. Desta forma, além da dedicação com o instrumento são necessárias ações que realizem intervenções na postura dos músicos e consequentemente nos tempos de trabalho, ajustes dos instrumentos e consciência corporal durante as atividades.

Com relação à queixeira, as propriedades que indicam menor pressão e força são as alturas relativas, formas e tamanhos (em termos de área total), os materiais utilizados para a fabricação, e a colocação no instrumento. Quanto maior a área de contato com o queixo menor a pressão e a força exercida. Outra característica importante e notável é em relação ao material utilizado, sendo espumas consideradas melhores (OKNER, KERNOZEK e WADE, 1997). Porém, assim como evidenciado nas queixeiras, ainda faltam explicações relacionadas especificamente as espaleiras utilizadas pelos instrumentistas. Além disso, segundo os mesmos autores a espaleira também é influenciada pela queixeira, o que faz necessária investigações associadas a ambos os acessórios para resultados mais conclusivos e que influenciem diretamente na performance instrumental.

Segundo KÖENIG (2007) a queixeira deve estar de acordo com o formato do maxilar do músico. Porém, mesmo que a autora enfatize que o conforto seja preconizado e que alguns músicos não sabem fazer o bom uso dos recursos que os acessórios oferecem, não há indicações de como o músico deve proceder para a regulação deste acessório demonstrando uma lacuna entre a teoria-prática o que acaba influenciando a otimização das atividades profissionais e beneficiando os quadros de doença em função do trabalho. Isto demonstra a necessidade de formulação de materiais que forneçam indicações de como esses procedimentos devem ser realizados, principalmente respeitando as características individuais.

Como identificado no presente estudo, as regulagens são determinadas pelo conforto sentido/percebido (ou para não se sentir desconforto) pelos instrumentistas. De maneira geral, o padrão encontrado na regulagem das espaleiras está principalmente relacionado ao ajuste 
de altura, sendo esta fixada na metade dos eixos para $70 \%$ maioria dos músicos. Assim como indica KÖENIG (2007) ainda são necessários maiores subsídios aos instrumentistas para que os mesmos façam melhores usos dos recursos disponibilizados pelos acessórios utilizados durante as atividades performáticas.

\section{5 - Considerações finais}

De acordo com as análises realizadas foi possível observar necessidades em se atender totalmente aos princípios de usabilidade visando maximização da funcionalidade de espaleiras. Os princípios de usabilidade necessitam ser repensados para que haja atendimento das necessidades dos instrumentistas frente às exigências das práticas musiciais.

Alternativas que busquem a melhoria do produto podem influenciar diretamente na satisfação dos instrumentistas para com suas espaleiras, já que a maior parte dos músicos acredita que as espaleiras são eficazes para as práticas instrumentais. Entretanto, os instrumentistas ainda acreditam que as espaleiras ainda precisam ser mais eficientes, fazendo com que não só a correta postura seja mantida, mas também que menores ocorrências de dores e/ou desconfortos musculoesqueléticos sejam geradas em função dos ajustes inadequados dos acessórios.

Na percepção dos instrumentistas, as modificações são necessárias tanto na estrutura quanto nos materiais utilizados para a construção das espaleiras. Maior adaptabilidade ao corpo e maior conforto são quesitos importantes a serem encontrados nos produtos e em especial nas espaleiras. Há também interesse de se entender como proceder para os corretos ajustes com as diferenças antropométricas e de dimensões do instrumento - o que traz a necessidade de estudos focados nessas investigações. Para tanto, outros estudos ainda são necessários, tanto com relação à espaleira quanto a queixeira utilizada pelos instrumentistas. Logo, sugeremse estudos que busquem relacionar a ergonomia das espaleiras e a antropometria corporal dos músicos. 


\section{Referências}

1.ANDRADE, E.Q.; FONSECA, J.G.M. (2000). Artista-atleta: reflexões sobre a utilização do corpo na performance dos instrumentos de cordas. Per Musi. v.2, p.118-128.

2.ANNA, M.W. (2000). Usability testing in 2000. Ergonomics. v.43, n.7, p.998-1006.

3.ARAÚJO, N.C.K.; CARDIA, M.C.G. (2005). A presença de vícios posturais durante a execução do violino. In: Congresso Brasileiro de Biomecânica, 10, João Pessoa, 2005. Anais... João Pessoa: Sociedade Brasileira de Biomecânica, CD-Rom.

4.BERKHOUT, A.L.; HENDRIKSSON-LARSÉN, K.; BONGERS, P. (2004). The effect of using a laptopstation compared to using a standard laptop PC on the cervical spine torque, perceived strain and productivity. Applied Ergonomics. v.35, p.147-152.

5.BERQUE, P., GRAY, H. (2002). The influence of neck-shoulder pain on trapezius muscle activity among professional violin and viola players: an electromyographic study. Medical Problems of Performing Artists. v.17, n.2, p.68-75.

6.BLUM, J.; RITTER, M.D. (1990). Violinists and violists with masses under the left side angle of the jaw known as "fiddler's neck". Medical Problems of Performing Artists. v.5, n.1, p.155-160.

7.BRANDFONBRENER, A. G. Interview with Cho-Liang (Jimmy) Lin. Medical Problems of Performing Artists. v.4, n.1, p.3-8, 1989.

8.BRANDFONBRENER, A. G. (1990). The epidemiology and prevention of hand and wrist injuries in performing artists. Hand Clinics. v.6, n.3, p.365-377.

9.CAMPOS, R.M.; COSTA, J.; FIGUEIREDO, D.; RABELO, V.; BRANDÃO, S.; FERREIRA, J.; PEREIRA, R.; CASTRO, I.S. (2006). O benefício da ergonomia para a arte de tocar o violino. In: Congresso Brasileiro de Ergonomia, 14, Curitiba, 2006. Anais... Curitiba: Associação Brasileira de Ergonomia, CD-Rom.

10.CYBIS, W.; BETIOL, A.H.; FAUST, R. (2007). Ergonomia e usabilidade: conceitos, métodos e aplicações. São Paulo: Novatec editora, 344p.

11.CORLETT, E.N.; BISHOP, R.P. (1976). A technique for assessing postural discomfort. Ergonomics. v.19, p.175-182.

12.COSTA, C. P. (2003). Quando tocar dói: Análise Ergonômica da Atividade de Violistas de Orquestra. 2003. 136f. Dissertação (Mestrado em Psicologia) - Universidade de Brasília, UNB, Brasília.

13.FJELLMAN-WIKLUNDA, A.; GRIPB, H.; KARLSSONB, J.S.; SUNDELINA, G. (2004). EMG trapezius muscle activity pattern in string players: Part I-is there variability in the playing technique? International Journal of Industrial Ergonomics. v.33, n.4, p.347-356. 
14.FRY, H.J.H. (1986a). Incidence of overuse syndrome in the symphony orchestra. Medical Problems of Performing Artists. v.1, p.51-55.

15.FRY, H.J.H. (1986b). Overuse syndromes in musicians-100 years ago. The Medical Journal of Australia. v.145, p.620-625.

16.GUÉRIN, F.; LAVILLE, A.; DANIELlOU, J. DURAFFOURG, A. (2001). Compreender o trabalho para transformá-lo: a prática da ergonomia. São Paulo: Edgard Blücher: Fundação Vanzolini. 224p.

17.HEMING, M.J.E. (2004). Occupational injuries suffered by classical musicians through overuse. Clinical Chiropractic. n.7, p.55-66.

18.HUNTER, J.H.; FRY, M.S. (1986). Incidence of overuse syndrome in the symphony orchestra. Medical Problems of Performing Artists. v.1, n.2, p.51-55.

19.IIDA, Í.(2005). Ergonomia projeto e produção. São Paulo: Edgar Blucher. 614p.

20.ISO 9241-11:1998. Ergonomic requirements for office work with visual display terminals (VDTs) - Part 11: Guidance on usability.

21.JORDAN, P. (1998). An introduction to usability. UK: Taylor \& Francis. 120p

22.KIM, J.; HAN, S.H. (2008). A methodology for developing a usability index of consumer electronic products. International Journal of Industrial Ergonomics. v.38, n.3-4, p.333345 .

23.KÖENIG, I. (2007). Dort e violino: propostas para um tocar saudável. 2007. 73f. Trabalho de conclusão de curso (Bacharelado em Música). Curso de Graduação em Música, Universidade do Estado de Santa Catarina.

24.LEVY, C.E.; LEE, W.A.; BRANDFONBRENER, A.G.; PRESS, J.; LEVY, A.E. (1992). Electromyographic analysis of muscular activity in the upper extremity generated by supporting a violin with and without a shoulder rest. Medical Problems of Performing Artists. v.7, n.4, p.103-109.

25.NORRIS, R. (1995). The musician's survival manual: a guide to preventing and treating injuries in instrumentalists. Saint Louis: MMB Music. 134p.

26.OKNER, M.A.O.; KERNOZEK, T.; WADE, M.G. (1997). Chin rest pressure in violin players: musical repertoire, chin rests, and shoulder pads as possible mediators. Medical Problems of Performing Artists. v.12, n.4, p.112-121.

27.PADILHA, E. (2001). Marketing para a engenharia, arquitetura e agronomia. Brasília: CONFEA. 208p.

28.PASCHOARELLI, L.C.; COURY, H.J.C.G. (2000). Aspectos ergonômicos e de usabilidade no design de pegas e empunhaduras. Estudos e Design, v.8, n.1, p.79-101.

29.PHILIPSON, L.S.; ORBYE, R.; LARSSON, P.; KALADJEV, S. (1990). Muscular load 
levels in performing musicians as monitored by quantitative electromyography. Medical Problems of Performing Artists. v.5, n.2, p.79-82.

30.PETRUS, Â. M. F. (2005). Produção musical e desgaste musculoesquelético: elementos condicionantes da carga de trabalho dos violinistas de uma orquestra. 2005. $116 \mathrm{f}$. Dissertação (Mestrado em Engenharia de Produção) - Universidade Federal de Minas Gerais, UFMG, Belo Horizonte.

31.PREECE, J.; ROGERS, Y.; SHARP, H. (2005). Design de Interação: Além da Interação homem-computador. Tradução Viviane Possamai. Porto Alegre: Bookman.

32.REINA, N. J.; HONET, J. C.; BROWN, W.; BEITMAN, M.; CHODOROFF, G. (1998). Paget-Schroetter syndrome in a viola player. Medical Problems of Performing Artists. v.3, n.1, p.24-25.

33.SILVEIRA, L. (2008). Ambientes modulares - uma proposta de conceito para concepção de ambientes interativos com foco em usuários novatos. 2008. 142f. Dissertação (Mestrado em Engenharia de Produção) - Universidade Federal de Santa Catarina, UFSC, Florianópolis.

34.STEINMETZ, A.; SEIDEL, W.; NIEMIER, K. (2008). Shoulder pain and holding position of the violin. Medical Problems of Performing Artists. v.23, n.2, p.79-81.

35.TEIXEIRA, C. S.; MERINO, E. A. D.; LOPES, L. F. D. (2008). A atividade do músico de orquestra: prática instrumental e desconforto corporal. In: CONGRESSO BRASILEIRO DE ERGONOMIA, 15, Porto Seguro, 2008. Anais... Porto Seguro, Associação Brasileira de Ergonomia, CD-ROM.

36.TEIXEIRA, C.S.; KOTHE, F.; PEREIRA, E.F.; MORO, A.R.P.; MERINO, E. A. D. (2009). Trabalho e prática de exercícios físicos: o caso de músicos de orquestra. Lecturas Educación Física $\mathbf{y}$ Deportes. v.13, n.130. Disponível em: $<$ http://www.efdeportes.com/efd130/exercicios-fisicos-o-caso-de-musicos-deorquestra.htm> Acesso em: 09 abril 2009.

37.TEIXEIRA, C.S.; KOTHE, F.; PEREIRA, É.F.; MERINO, E.A.D. (2012). Avaliação da postura corporal de trabalho de violinistas e violistas. Per Musi. v.26, p.140-150.

38.TEIXEIRA, C.S. (2011). Fatores associados às queixas musculoesqueléticas no contexto das condições de saúde e trabalho de instrumentistas de corda, considerando a ergonomia organizacional, cognitiva e física. 279f. Tese (Doutorado em Engenharia de Produção) - Universidade Federal de Santa Catarina, UFSC, Florianópolis.

39.THOMAS, J. R.; NELSON, J. K. (2002). Métodos de pesquisa em atividade física. Porto Alegre: ArtMed. 419p

40.VERGARA, M.; PAGE, Á. (2002). Relationship between comfort and back posture and mobility in sitting-posture. Applied Ergonomics. v.33, n.1, p.1-8.

41.VAN DER LINDEN, J.C.S.; GUIMARÃES, L.B.M. (2006). Modelo descritivo para a percepção de conforto e de risco. In: Congresso Brasileiro de Ergonomia, 14, Curitiba, 2006. 
Anais... Curitiba, Associação Brasileira de Ergonomia, CD-ROM.

42.WINSPUR, I.; PARRY, C.B.W. (1997). The musician's hand. Journal of Hand Surgery. v.22, n.4, p.433-440.

Notas sobre os autores

Fausto Kothe: Possui graduação em Música (bacharelado em viola) pela Universidade Federal de Santa Maria (2004). Já participou das atividades da Orquestra Sinfônica de Porto Alegre (OSPA), Orquestra Sinfônica do Paraná (OSINPA), Orquestra Sinfônica de Caxias do Sul, Orquestra Sinfônica da UNISINOS, Orquestra Sinfônica de Santa Maria, Orquestra Jovem UNISC, Orquestra Sinfônica de Santa Catarina (OSSCA), Camerata Florianópolis, Orquestra Filarmônica de Jaraguá do Sul, Orquestra de Câmara de Caçador e Orquestra da Universidade Positivo. Atuou na docência durante os anos de 2006-2009 em escolas do ensino médio e fundamental e entre os anos de 2011-2013 como professor do curso de Música da Universidade do Estado de Santa Catarina. Tem mestrado em Música pela Universidade Federal do Paraná

Clarissa Stefani Teixeira: Professora do Departamento de Engenharia do Conhecimento da Universidade Federal de Santa Catarina. Doutora em Engenharia de Produção pela UFSC. Tem formação tutorial em Educação a Distância pela UFPR e experiência profissional na docência do ensino à distância. Tem experiência em elaboração e gestão de projetos com órgãos de fomento e financiamento como: Banco Interamericano de Desenvolvimento (BID) e Banco Nacional de Desenvolvimento Econômico e Social (BNDES). Atua nas linhas de pesquisa de saúde se segurança do trabalhador.

Érico Felden Pereira: É professor Universidade do Estado de Santa Catarina. Possui graduação, mestrado e doutorado em Educação Física e é especialista em Atividade Física, Desempenho Motor e Saúde. É professor do Programa de Pós-Graduação Stricto Sensu em Ciências do Movimento Humano da UDESC nas linhas de pesquisa Atividade Física e Saúde e Comportamento Motor. Tem experiência nas áreas de Educação Física e Saúde atuando, especialmente, nos seguintes temas: aprendizagem motora e desenvolvimento humano, ciclo vigília/sono, saúde do trabalhador e imagem corporal. 
Eugenio Andrés Díaz Merino: Possui graduação em Desenho Industrial pela Universidade Federal do Rio de Janeiro (1993), mestrado em Engenharia de Produção pela Universidade Federal de Santa Catarina (1996) e doutorado em Engenharia de Produção pela Universidade Federal de Santa Catarina (2000). Atualmente é professor da Universidade Federal de Santa Catarina e coordena o Núcleo de Gestão de Design e Laboratório de Design e Usabilidade. 